\title{
Holmium-YAG laser: impact of pulse energy and frequency on local fluid temperature in an in-vitro obstructed kidney calyx model
}

Michael W. Sourial

Joshua Ebel

Nathaly Francois

Geoffrey N. Box

Bodo E. Knudsen 


\title{
Holmium-YAG laser: impact of pulse energy and frequency on local fluid temperature in an in-vitro obstructed kidney calyx model
}

\author{
Michael W. Sourial, ${ }^{*}$ Joshua Ebel, Nathaly Francois, Geoffrey N. Box, and Bodo E. Knudsen \\ The Ohio State University Wexner Medical Center, Department of Urology, Columbus, Ohio, United States
}

\begin{abstract}
During laser lithotripsy, energy is transmitted to both the stone and the surrounding fluid. As the energy is delivered, the temperature will rise. Temperatures $\geq 60^{\circ} \mathrm{C}$ can cause protein denaturation. The objective of this study is to determine the time it takes from body temperature $\left(37^{\circ} \mathrm{C}\right)$ to $60^{\circ} \mathrm{C}$ at various laser power settings. A Flexiva TracTip 200 optical fiber was submerged alongside a negative temperature coefficient-type thermistor in $4 \mathrm{~mL}$ of saline in a glass test tube. A Lumenis VersaPulse Powersuite 100-W holmium:yttrium aluminum garnet laser was activated at $0.2-$ to $1.5-\mathrm{J}$ pulse energies, $6-$ to $50-\mathrm{Hz}$ frequencies, and 2- to 22.5-W average power. Temperature readings were recorded every second from $37^{\circ} \mathrm{C}$ until $60^{\circ} \mathrm{C}$. Time and heating rate were measured. The procedure was repeated three times for each setting. Average time from $37^{\circ} \mathrm{C}$ to $60^{\circ} \mathrm{C}$ for settings (1) $0.2 \mathrm{~J} / 50 \mathrm{~Hz}$, (2) $0.6 \mathrm{~J} / 6 \mathrm{~Hz}$, (3) $1 \mathrm{~J} / 10 \mathrm{~Hz}$, and (4) $1.5 \mathrm{~J} / 10 \mathrm{~Hz}$ was 60.3 , $172.7,58$, and $43.3 \mathrm{~s}$, respectively. Time from $37^{\circ} \mathrm{C}$ to $60^{\circ} \mathrm{C}$ decreased as frequency increased for every given pulse energy. Average heating rate increased proportionally to power from $0.06^{\circ} \mathrm{C} / \mathrm{s}$ at $2 \mathrm{~W}$ to $0.74^{\circ} \mathrm{C} /$ $\mathrm{s}$ at $22.5 \mathrm{~W}$. During laser lithotripsy, there is a rapid increase in the temperature of its surrounding fluid and temperatures $\geq 60^{\circ} \mathrm{C}$ may be reached. This could have local tissue effects and some caution with higher power settings should be employed especially where irrigation is limited. Further studies incorporating irrigation and live tissue models may aid to further define the risks. @2018 Society of Photo-Optical Instrumentation Engineers (SPIE) [DOI: 10 1117/1.JBO.23.10.105002

Keywords: calculi; lithotripsy; laser; temperature; protein denaturation.
\end{abstract}

Paper 180392R received Jun. 29, 2018; accepted for publication Sep. 21, 2018; published online Oct. 9, 2018.

\section{Introduction}

The prevalence of kidney stones in the United States is estimated to be $8.8 \%$, based on a recent cross-sectional survey. ${ }^{1}$ This has translated into an increase in ureteroscopies performed to treat urolithiasis, with a $251.8 \%$ increase in ureteroscopies performed between 2004 and $2016 .^{2}$ The lithotrite of choice remains the holmium:yttrium aluminum garnet (Ho:YAG) laser for patients undergoing ureteroscopy.,

Optical fibers transmit energy to fragment stones, and their safety profile has been previously shown to be favorable compared to other lithotrites, particularly regarding their low risk of ureteral perforation. ${ }^{5-7}$ This is in part due to the 2140 -nm wavelength of the Ho:YAG laser that permits rapid absorption in water.

It has been previously shown that temperatures of as low as $60^{\circ} \mathrm{C}$ can cause protein denaturation..$^{8-10}$ With the increased use of high-powered lasers for lithotripsy, which can deliver both high pulse energy and frequency, understanding the heat impact is an important safety consideration. Higher temperatures may lead to potential cell damage of the urothelium or renal parenchyma. A few recent series have reported on the temperature rise with laser activation. ${ }^{11-13}$

The objective of this in-vitro study is to determine the time it takes after laser activation to heat fluid from body temperature $\left(37^{\circ} \mathrm{C}\right)$ to $60^{\circ} \mathrm{C}$ at selected laser energy and frequency settings.

*Address all correspondence to: Michael W. Sourial, E-mail: Michael.sourial@ osumc.edu

\section{Materials and Methods}

\subsection{Laser}

The set of experiments was performed using the Lumenis VersaPulse Powersuite 100-W laser (Lumenis Ltd., Yokneam, Israel), a fixed short pulse laser. Pulse energy settings of 0.2 , $0.6,1.0$, and $1.5 \mathrm{~J}$ were used. Frequency settings of 10, 20, 30,40 , and $50 \mathrm{~Hz}$ were tested at the $0.2-\mathrm{J}$ pulse energy setting, and $6,8,10$, and $15 \mathrm{~Hz}$ were tested at all other pulse energy settings. The energy and frequency settings selected reflect laser settings commonly used to fragment stones in clinical practice and also to demonstrate the effect of successive increases in frequency when energy remained constant.

The optical fiber used was the Flexiva TracTip 200 fiber (Boston Scientific, Marlborough, Massachusetts). Energy output of the laser and optical fiber setup was verified using a Coherent EnergyMax 400 detector (Coherent, Santa Clara, California) to ensure proper calibration. The energy settings were tested for a total of 50 pulses and the average energy was recorded. The calculated error rate represents the difference between energy output on the clinical laser screen and what was actually measured on the external energy meter during calibration.

\subsection{Study Design}

The average volume of a dilated calyx was estimated by surface area measurements of $10 \mathrm{CT}$ scans as previously described. ${ }^{14}$ This was estimated to be $4 \mathrm{~mm}$. This volume of normal saline

$1083-3668 / 2018 / \$ 25.00$ @ 2018 SPIE 

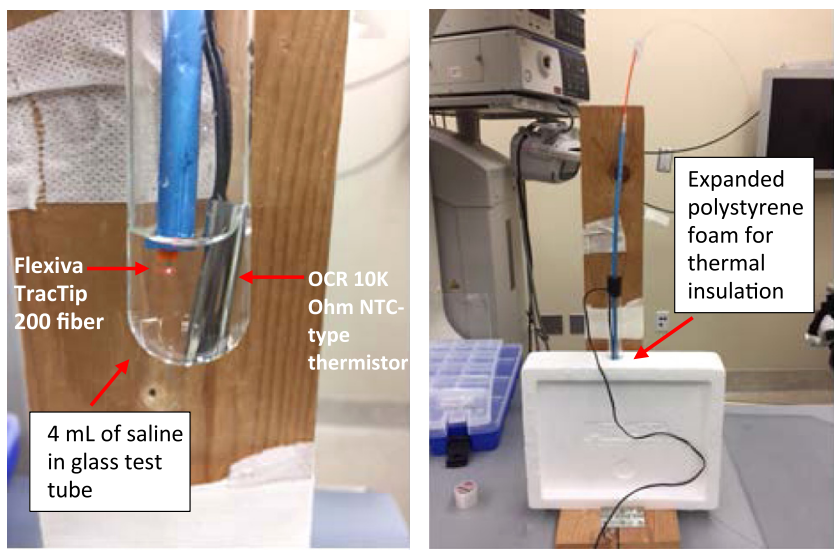

Fig. 1 (a) and (b) In-vitro setup of optical fiber, thermistor, and expanded polystyrene foam.

was placed in a glass test tube. The Flexiva TracTip 200 optical fiber was submerged in the saline alongside an $\mathrm{OCR}^{\mathrm{TM}} 10 \mathrm{~K} \mathrm{Ohm}$ negative temperature coefficient-type thermistor with an accuracy of $1 \%$ to record temperature, as shown in Fig. 1(a). The glass test tube was thermally insulated using expanded polystyrene foam [Fig. 1(b)]. The ambient room temperature was $22.5^{\circ} \mathrm{C}$

\subsection{Theoretical Predictions}

Theoretical heating rates were calculated using the calorimetry Eq. (1) as derived from the first law of thermodynamics, where $\Delta T$ is the change in temperature, $Q$ is the heat, and $m c$ correspond to the mass and specific heat of the involved substance.

$\Delta T=\frac{Q}{m c}$.

Given that heating is equal to the pulse energy $\left(E_{p}\right) \times$ the frequency of the laser $(f)$ over time [Eq. (2)], we can derive Eq. (3) for the predicted heating for a given time.

$Q=E_{p} f(t)$,

$\Delta T=\frac{f E_{p}}{m c}(t)$.

Given that $m c$ is the summation of substances in the system and the heat transference to the glass container would be variable over the experiment, the saline solution and the sensor were factored in to calculate the upper range of predicted heating where as the glass container was factored in to calculate the lower range of predicted heat.

\subsection{Measurements}

The laser was activated and temperature readings were recorded once per second from $37^{\circ} \mathrm{C}$ until $60^{\circ} \mathrm{C}$, and the time was recorded. Heating rate was calculated from these measurements. The procedure was repeated three times for each setting. Predicted values were also calculated based on the heat capacity equation for mixed substances as derived from the first law of thermodynamics. The upper range of predicted heating was calculated without considering the glass holding container in our experimental setup, whereas the lower range of predicted heating took this into consideration.

\subsection{Statistics}

Statistical evaluation included calculations of the means and standard deviations for each experiment and their graphical representation. Linear regression was used to assess the relationship between predicted and experimental heating rates. Calculations were carried out using Microsoft Excel 2013 Professional edition and graphs were made using R-version 3.2.3.

\section{Results}

Laser energy output was verified to be properly calibrated, with a calculated error range of $1.6 \%$ to $7.0 \%$. No adjustments were made to the collected data since this error rate was considered insignificant.

The mean time $( \pm \mathrm{SD})$ from $37^{\circ} \mathrm{C}$ to $60^{\circ} \mathrm{C}$ decreased as power increased, ranging from $31( \pm 1) \mathrm{s}$ at the highest power setting $(22.5 \mathrm{~W})$ to $355( \pm 5.3) \mathrm{s}$ at the lowest power setting $(2 \mathrm{~W})$. The heating rate increased as power increased, ranging from $0.06^{\circ} \mathrm{C} /$ $\mathrm{s}$ at the lowest power setting $(2 \mathrm{~W})$ to $0.74^{\circ} \mathrm{C} / \mathrm{s}$ at the highest power setting $(22.5 \mathrm{~W})$. The time from $37^{\circ} \mathrm{C}$ to $60^{\circ} \mathrm{C}$ and heating rates are shown in Table 1. At a given pulse energy, the time to $60^{\circ} \mathrm{C}$ decreased and the heating rate increased as frequency increased (Fig. 2).

Predicted heating rates from $37^{\circ} \mathrm{C}$ to $60^{\circ} \mathrm{C}$ ranged between $0.6^{\circ} \mathrm{C} / \mathrm{s}$ and $0.12^{\circ} \mathrm{C} / \mathrm{s}$ in the lowest power setting $(2 \mathrm{~W})$. At

Table 1 Time from $37^{\circ} \mathrm{C}$ to $60^{\circ} \mathrm{C}$ and heating rate at tested laser settings.

\begin{tabular}{|c|c|c|c|c|c|}
\hline $\begin{array}{l}\text { Energy } \\
\text { (J) }\end{array}$ & $\begin{array}{l}\text { Frequency } \\
\qquad(\mathrm{Hz})\end{array}$ & $\begin{array}{l}\text { Power } \\
\text { (W) }\end{array}$ & $\begin{array}{c}\text { Mean time } \\
\text { from } 37^{\circ} \mathrm{C} \\
\text { to } 60^{\circ} \mathrm{C} \\
(\mathrm{S} \pm \mathrm{SD})\end{array}$ & $\begin{array}{l}\text { Mean } \\
\text { heating } \\
\text { rate } \\
\left({ }^{\circ} \mathrm{C} / \mathrm{s}\right)\end{array}$ & $\begin{array}{l}\text { Predicted } \\
\text { heating } \\
\text { rates } \\
\left({ }^{\circ} \mathrm{C} / \mathrm{s}\right)\end{array}$ \\
\hline 0.2 & 10 & 2 & $355.0 \pm 5.3$ & 0.06 & 0.06 to 0.12 \\
\hline 0.2 & 20 & 4 & $162.7 \pm 4.9$ & 0.14 & 0.12 to 0.23 \\
\hline 0.2 & 30 & 6 & $99.0 \pm 2$ & 0.23 & 0.18 to 0.35 \\
\hline 0.2 & 40 & 8 & $81.3 \pm 7.5$ & 0.28 & 0.24 to 0.46 \\
\hline 0.2 & 50 & 10 & $60.3 \pm 2.9$ & 0.38 & 0.30 to 0.58 \\
\hline 0.6 & 6 & 3.6 & $172.7 \pm 14$ & 0.13 & 0.11 to 0.21 \\
\hline 0.6 & 8 & 4.8 & $127.3 \pm 9.1$ & 0.18 & 0.14 to 0.28 \\
\hline 0.6 & 10 & 6 & $95.7 \pm 4$ & 0.24 & 0.18 to 0.35 \\
\hline 0.6 & 15 & 9 & $64.0 \pm 2$ & 0.36 & 0.27 to 0.52 \\
\hline 1 & 6 & 6 & $100.3 \pm 8.4$ & 0.23 & 0.18 to 0.35 \\
\hline 1 & 8 & 8 & $76.3 \pm 2.5$ & 0.30 & 0.24 to 0.46 \\
\hline 1 & 10 & 10 & $58.0 \pm 1.7$ & 0.40 & 0.30 to 0.58 \\
\hline 1 & 15 & 15 & $42.0 \pm 2$ & 0.55 & 0.45 to 0.87 \\
\hline 1.5 & 6 & 9 & $70.7 \pm 4$ & 0.33 & 0.27 to 0.52 \\
\hline 1.5 & 8 & 12 & $57.0 \pm 5.6$ & 0.40 & 0.36 to 0.69 \\
\hline 1.5 & 10 & 15 & $43.3 \pm 2.3$ & 0.53 & 0.45 to 0.87 \\
\hline 1.5 & 15 & 22.5 & $31.0 \pm 1$ & 0.74 & 0.68 to 1.30 \\
\hline
\end{tabular}




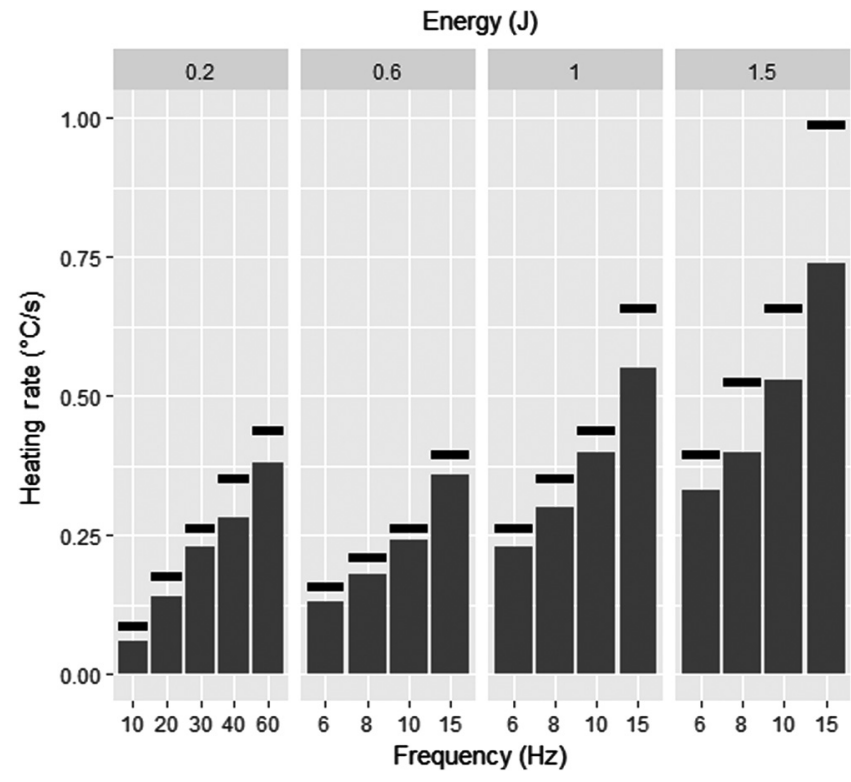

Fig. 2 Measured heating rates $\left({ }^{\circ} \mathrm{C} / \mathrm{s}\right)(y$-axis) as a function of laser energy $(J)$ (top $x$-axis) and frequency $(\mathrm{Hz})$ (bottom $x$-axis). Black bars represent the average of the upper and lower predicted heating rates.

the highest power setting $(22.5 \mathrm{~W})$, predicted values ranged from $0.76^{\circ} \mathrm{C} / \mathrm{s}$ to $1.3^{\circ} \mathrm{C} / \mathrm{s}$. All experimental values fell within the lower and upper bounds of our prediction (Table 1). In both scenarios, there was a close linear relationship between the predicted and experimental values $\left(R^{2}=0.99\right)$.

\section{Discussion}

The Ho:YAG laser is currently the lithotrite of choice for performing ureteroscopy. The safety profile has been shown to be favorable compared to other lithotrites, particularly regarding the low risk of ureteral perforation. ${ }^{5-7}$ Optical fibers are being commercially produced with an increased ability to withstand higher power settings. Although this has led to better performing and durable fibers, only recently have studies been done specifically evaluating the deleterious effects of working at these higher settings. ${ }^{11,12}$ The process of fragmenting calculi by the Ho:YAG laser at various pulse durations has been previously described. ${ }^{15,16}$ At longer pulse durations ( $\left.>100 \mu \mathrm{s}\right)$, the acoustic waves that accompany the collapse of vapor bubbles were of insufficient pressure magnitude to mechanically damage or fragment calculi. The mechanism of fragmentation with longer pulse duration is primarily "photothermal," with increasing thermal collateral damage as pulse duration increased $(>20 \mathrm{~ms}) .{ }^{15}$

Protein denaturation can occur as a result of photothermal injury, which involves disruption of the secondary, tertiary, or quaternary structure of the protein's original state and can be reversible or irreversible. Vermeer et al. ${ }^{8,9}$ studied the process of denaturation of immunoglobulin $\mathrm{G}(\mathrm{IgG})$ and showed two main transitions that are a superimposition of distinct denaturation steps. The two transitions had different sensitivities to changes in temperature and $\mathrm{pH}$. The two peaks represent the $\mathrm{Fab}$ and $\mathrm{Fc}$ fragments of the IgG molecule. They demonstrated that denaturation occurred in two transitions, one at $61^{\circ} \mathrm{C}$ and another at $71^{\circ} \mathrm{C}$, corresponding to the $\mathrm{Fab}$ and $\mathrm{Fc}$ fragment, respectively. Moreover, after cooling the sample, the thermogram of a subsequent cycle did not show any peak, indicating irreversible denaturation. Similarly, Cerasoli et al. ${ }^{10}$ looked at
IgG proteins being used as drug molecules and showed structural changes at a temperature of $61^{\circ} \mathrm{C}$. Protein denaturation may be reversible in the $40^{\circ} \mathrm{C}$ to $47^{\circ} \mathrm{C}$ range; ${ }^{17}$ however, these lower temperatures could still result in renal damage if the kidney is exposed for prolonged periods of time.

The relationship between the temperature and time of exposure in cancer therapy has been described in a theoretical, mathematical model to calculate a "thermal dose" of therapy. Using $43^{\circ} \mathrm{C}$ as a reference point, their calculations provide a T43 equivalence (equating time at one temperature with an equivalent time for the same effect at another temperature). This relationship is exponential in their models, and a rise in temperature of a few degrees can significantly reduce the time necessary for cell injury and death. Other factors that can alter the calculated times include $\mathrm{pH}$, tumor location, high tumor blood flow, varying tissue or cellular sensitivities to heat, or a combination thereof. ${ }^{18}$ After focally treating porcine kidneys with microwave therapy (50 W for $10 \mathrm{~min}$ ), He et al. ${ }^{19}$ demonstrated thermally induced injury (no temperatures mentioned), with a threshold for microvascular injury that appeared to be lower than that for renal epithelial cell injury.

Our study aims to evaluate the impact of increasing laser power settings on the surrounding fluid temperature. The invitro setup represents an obstructed calyx where there is little room for outflow of fluid with the ureteroscope positioned in a narrow infundibulum. It may also simulate a smaller renal pelvis with a tight ureteropelvic junction that coaptates around the ureteroscope and limits outflow. In these settings, where a laser may be activated continuously for long periods of time in a confined space with poor outflow, the concern for local heating is raised. When testing commonly used laser settings, such as $1 \mathrm{~J} /$ $10 \mathrm{~Hz}$ or $0.2 \mathrm{~J} / 50 \mathrm{~Hz}(10 \mathrm{~W})$, the time it takes to reach $60^{\circ} \mathrm{C}$ is about $1 \mathrm{~min}$ (Table 1). The time is even shorter with higher power settings. Urologists should be aware of this rapid and substantial rise in temperature and its possible safety implications, such as potentially irreversible damage to the urothelium and renal parenchyma. Periodically stopping laser activation would be prudent, especially in situations where there is limited irrigant flow, such as working in a calyx with a very tight infundibulum. Future innovations, such as temperature sensors on ureteroscopes, may allow for active monitoring of temperature during the procedure.

In an ex-vivo model using Ovis aries urinary tracts, Molina et al..$^{20}$ recorded a temperature rise to $112.4^{\circ} \mathrm{C}$ without irrigation using Ho:YAG laser settings of $1 \mathrm{~J} / 10 \mathrm{~Hz}$. When irrigation from a saline bag at $3 \mathrm{ft}(8 \mathrm{~mL} / \mathrm{s})$ was applied, this reduced the temperature to $49.7^{\circ} \mathrm{C}$. This was the first study exploring the effect of Ho:YAG laser on surrounding temperature in a ureteral model. More recent in-vitro studies confirm our results. Butticè et al. ${ }^{13}$ used the K-box ${ }^{\circledR}$ polyurethane model (Coloplast, Humlebaek, Denmark) and demonstrated rapid rises in temperatures similar to our results. Their study showed a more pronounced rise with a larger laser fiber (272 versus $200 \mu \mathrm{m}$ ); however, this was not statistically significant. The volume of saline used was $10 \mathrm{~mL}$ in a large saline-filled heating tank, which yielded a wide range of heating rates at the same laser setting (i.e., $1 \mathrm{~J} / 10 \mathrm{~Hz}$ settings yielded heating rates of $0.05^{\circ}$ $\mathrm{C} / \mathrm{s}$ to $0.16^{\circ} \mathrm{C} / \mathrm{s}$ ) and also occasional nonlinearity of the resultant heating curves, potentially due to heat transfer in the polyurethane model and an initial temperature lag. In contrast to our study, laser settings tested were mainly lower frequencies $(0.5 \mathrm{~J} / 20 \mathrm{~Hz}, 1 \mathrm{~J} / 10 \mathrm{~Hz}$, and 2 to $5 \mathrm{~J} / 5 \mathrm{~Hz}$ ) which may limit 
the applicability to lower energy/higher frequency "dusting" settings more commonly used today. They also showed that open irrigation limited the temperature rise with any laser setting. One major limitation of their system is the use of an endotracheal thermometer with an upper limit of $45^{\circ} \mathrm{C}$.

In a "calyceal model" where temperature of deionized water in a glass test tube similar to the current model was recorded at various laser settings activated for $60 \mathrm{~s}$, Aldoukhi et al. ${ }^{12}$ noted that the highest temperature rise was to $70^{\circ} \mathrm{C}$ using their highest setting power setting $(1 \mathrm{~J} / 40 \mathrm{~Hz})$ with no irrigation. Wollin et al. ${ }^{11}$ evaluated the temperature rise in an in-vitro ureteral model at various laser settings in the span of a 60-s laser activation window. With no irrigation flow, boiling point temperatures $\left(>100^{\circ} \mathrm{C}\right)$ were reached using their highest laser settings $(1 \mathrm{~J} / 20 \mathrm{~Hz})$ in $<60 \mathrm{~s}$. When irrigation flow was set at both 50 and $100 \mathrm{~mL} / \mathrm{min}$, temperature rise at all laser settings was less substantial. The constant irrigation flow in the model may generate high intrarenal pressures and may not apply to real-life situations, such as when flow is absent or in cases with user-operated hand pumps (Single Action Pumping System, Boston Scientific, Marlborough, Massachusetts or the Pathfinder Plus, Utah Medical products, Midvale, Utah). Both studies confirm the rapid rise in temperature in situations with no irrigation flow as demonstrated in our model. Although Ho:YAG laser lithotripsy is still considered very safe, the current and previously discussed studies demonstrate a potentially harmful effect of Ho:YAG laser lithotripsy and is of particular importance as increasingly high-powered lasers are used to fragment stones. $^{21}$

Limitations to the study include the in-vitro nature of the experiment. Also, we did not measure the effects of various stone compositions, irrigation, or intermittent laser stoppage, which reduces the applicability of our results to every day ureteroscopy usage. The temperature at which urothelial protein denaturation occurs is not precisely known. Furthermore, the rate of heating of any substance will be greatly affected by the temperature, heat capacity, and heat transfer coefficient of its container as demonstrated by the error range in predicted values in our in-vitro experimental setup. The heat sink effect of the kidney in the in-vivo setting and its effect on heating rate remains to be elucidated in future studies. This study evaluates the heat impact of the laser, quantifying heating rates, and demonstrating rapid rise of heating rates with increasing laser power settings. This is particularly important as higher laser power settings are being increasingly used to fragment stones.

Future studies should attempt to replicate these findings in vivo and incorporate irrigation and/or intermittent laser stoppage to replicate real-life usage of the laser. Studies should also attempt to quantify the impact of heat on surrounding urothelium, renal parenchyma, and surgical equipment, such as access sheaths or ureteroscopes.

\section{Conclusion}

Use of lasers, and particularly at higher power settings, can cause a rapid and substantial increase in the temperature of its surrounding fluid. This could have local tissue effects and some caution with higher pulse energy and frequency should be employed.

\section{Disclosures}

Dr Bodo E. Knudsen is a consult for Boston Scientific, Bard, and Olympus. This research was completed without their participation, knowledge, or financial support, and data were acquired and processed by coauthors unaffiliated with any commercial entity.

\section{References}

1. C. D. Scales et al., "Prevalence of kidney stones in the United States," Eur. Urol. 62, 160-165 (2012).

2. R. Geraghty, P. Jones, and B. K. Somani, "Worldwide trends of urinary stone disease treatment over the last two decades: a systematic review," J. Endourol. 31(6), 547-556 (2017).

3. D. Assimos et al., "Surgical management of stones: American Urological Association/Endourological Society guideline, part I," J. Urol. 196, 1153-1160 (2016).

4. D. Assimos et al., "Surgical management of stones: American Urological Association/Endourological Society guideline, part II," J. Urol. 196, 1161-1169 (2016).

5. J. M. Teichman et al., "Ureteroscopic management of ureteral calculi: electrohydraulic versus holmium:YAG lithotripsy," J. Urol. 158, $1357-$ 1361 (1997).

6. R. W. Santa-Cruz, R. J. Leveillee, and A. Krongrad, "Ex vivo comparison of four lithotripters commonly used in the ureter: what does it take to perforate?" J. Endourol. 12, 417-422 (1998).

7. S. S. Jeon, J. H. Hyun, and K. S. Lee, "A comparison of holmium:YAG laser with lithoclast lithotripsy in ureteral calculi fragmentation," Int. J. Urol. 12, 544-547 (2005).

8. A. W. Vermeer and W. Norde, "The thermal stability of immunoglobulin: unfolding and aggregation of a multi-domain protein," Biophys. J. 78, 394-404 (2000).

9. A. W. Vermeer, W. Norde, and A. van Amerongen, "The unfolding/ denaturation of immunogammaglobulin of isotype $2 b$ and its $F(a b)$ and F(c) fragments," Biophys. J. 79, 2150-2154 (2000).

10. E. Cerasoli et al., "Temperature denaturation and aggregation of a multidomain protein (IgG1) investigated with an array of complementary biophysical methods," Anal. Bioanal. Chem. 406, 6577-6586 (2014).

11. D. A. Wollin et al., "Effect of laser settings and irrigation rates on ureteral temperature during holmium laser lithotripsy, an in vitro model," J. Endourol. 32, 59-63 (2018).

12. A. H. Aldoukhi et al., "Thermal response to high-power holmium laser lithotripsy," J. Endourol. 31, 1308-1312 (2017).

13. S. Butticè et al., "Temperature changes inside the kidney: what happens during holmium:yttrium-aluminium-garnet laser usage?" J. Endourol. 30, 574-579 (2016).

14. H. Danuser et al., "Endopyelotomy for primary ureteropelvic junction obstruction: risk factors determine the success rate," J. Urol. 159, 56-61 (1998).

15. K. F. Chan et al., "A perspective on laser lithotripsy: the fragmentation processes," J. Endourol. 15, 257-273 (2001).

16. G. J. Vassar et al., "Holmium: YAG lithotripsy: photothermal mechanism," J. Endourol. 13, 181-190 (1999).

17. A. Schön et al., "Temperature stability of proteins: analysis of irreversible denaturation using isothermal calorimetry," Proteins 85, 20092016 (2017).

18. S. A. Sapareto and W. C. Dewey, "Thermal dose determination in cancer therapy," Int. J. Radiat. Oncol. Biol. Phys. 10, 787-800 (1984).

19. X. He et al., "Investigation of the thermal and tissue injury behaviour in microwave thermal therapy using a porcine kidney model," Int. J. Hyperthermia 20, 567-593 (2004).

20. W. R. Molina et al., "Influence of saline on temperature profile of laser lithotripsy activation," J. Endourol. 29, 235-239 (2015).

21. J. Tracey et al., "Ureteroscopic high-frequency dusting utilizing a 120 W holmium laser," J. Endourol. 32(4), 290-295 (2018).

Biographies for the authors are not available. 